\title{
Study effects of El Jadida-Casablanca industrial zone neighbouring areas
}

\author{
Huberson Douo Bogbe Gogon ${ }^{1}$, Hassane Erramli $^{2 *}$, Thierry Sauvage ${ }^{3}$, Claire Ramboz $^{4}$ \\ ${ }^{1}$ Université Felix Houphouët Boigny d'ABIDJAN Cocody UFR SSMT, Laboratoire de Physique Nucléaire et Radioprotection, Abi- \\ djan, d'Ivoire \\ ${ }^{2}$ Nuclear Physics and Techniques Laboratory, Faculty of Sciences Semlalia, University Cadi Ayyad, Marrakech, Morocco; \\ ${ }^{*}$ Corresponding Author: erramli@yahoo.com \\ ${ }^{3} \mathrm{CNRS} / \mathrm{CEMHTI}$, Site Cyclotron, Orléans, France \\ ${ }^{4}$ Institut des Sciences de la Terre d'Orléans (ISTO), Orléans, France
}

Received 14 September 2012; revised 24 December 2012; accepted 8 January 2013

Copyright (C) 2013 Huberson Douo Bogbe Gogon et al. This is an open access article distributed under the Creative Commons Attribution License, which permits unrestricted use, distribution, and reproduction in any medium, provided the original work is properly cited.

\begin{abstract}
The analytical technique PIXE experiment for measuring light and heavy elements concentration inside different samples of soil and residual water collected in the region of Safi-El Jadida, where an industrial complex resided, was performed. The same method was used to investigate the presence of elements ranging from silicon to lead in different soils samples and seaweed collected upstream from the site of Safi-EI Jadida industrial zone, inside lands and downstream of it, in the entrance of the Casablanca region. This study allows us to highlight the influence of activities of this industrial zone on the neighbouring areas the site.
\end{abstract}

Keywords: PIXE; Heavy And Light Elements; Van De Graaff Accelerator; Pollution; Phosphate Industry Waste

\section{INTRODUCTION}

Pollution is a phenomenon which indicates the degradation by the introduction of pollutants said matter, the increase or the change of shape of already present elements. Thus it creates more or less considerable disturbance of the ecosystems. For that purpose the presence of the industrial complex situated between Safi and El Jadida calls us. Representing the national capital of the chemical industry, the region abounds in a dense and diversified industrial fabric. It has positive effects on the welcome infrastructure, the development of the communication networks, the habitat sector, the trade, and jobs promotion. However this industrialization, associated to the demographic expansion in this region is also a big source of pollution in particular for waters and soils (water pollution, degradation of grounds, loss of biodiversity, destruction of the natural circles and the landscapes, etc.).

So these activities influence, on one hand, the quantities of oligo-element naturally present in the ground, which play an indispensable role for the food and the growth of plants; on the other hand, they contribute to the introduction of certain elements which are integral parts of the trace elements, and which are sometimes witnesses of the geochemical processes involved in the genesis and the evolution of the ground.

The studied influence of the industry on the coast between the Safi and El Jadida region was realized [1]. However, it is important to delimit the perimeter of repercussion of the industrial activities present on the whole Atlantic coast. It is in this sense that we collected various samples of soils of the neighbouring zones. The takings localized upstream are situated inside lands, in the plain and the sahel of Doukkala, between Sidi Bennour and El Jadida region. It is the zone which is considered as the capital of Doukkala as for the breeding and for the agricultural production, in the sense that it constitutes the first supplier of the region in meat and in vegetables. In addition, this region has an industrial complex especially based on the sugar production, which is the largest in Morocco.

We made another taking downstream the Safi-El Jadida industrial zone. These samples are exactly situated in the south of the Doukkala region, in the entrance of the Casablanca region. Casablanca is the region which generates $25 \%$ of the national GDP, with a strong Industrialization ( $42 \%$ of industries concerns), and takes the first position of industrial cities with approximately $50 \%$ 
of the factories of the country.

Several methods are used to identify and estimate the contagion of a site. We used in this work the method PIXE to study the pollution of waters and soils in the neighbourhood of the industrial site because of its sensibility and of its reliability, its speed, its non-destructive and its multi elementary. It is the physico chemical method that was developed in 1970 in Lund Institute of Technology by Johansson et al. [2], and whose domain extends over almost all the periodic table.

\section{EXPERIMENTAL METHOD}

Ten solid samples among which are 9 soil samples (S7 S15) and one seaweed sample (SW1) were collected upstream to the industrial complex of Jorf Lasfar (Figure 1), dried, pounded then homogenized. S7 was taken in the region of Sidi Bennour which shelters the sugar industries (2 km towards El Jadida). S9 was directly collected on a blackish deposit in border of the road going towards Jorf Lasfar. S8, S10 and S11 were collected in the same place, few meters next to the precedent sample. S12 was collected on the road of the Jorf Lasfar port, not far from the sea. As for S13, S14, S15 and SW1, they were respectively taken next to the discharge of some factories, on the discharge of a factory not far from the port, on the beach of Moulay Abdellah Amghar approximately $8 \mathrm{~km}$ from El Jadida and in the sea (seaweed of this beach). Seven other samples of soils (S16 - S22) were taken downstream to the site (Figure 1) and were subjected to the same treatment. They result from various beaches (S16 - S18) and fields (S19) as we progress in the direction of Casablanca. S20 to S22 were collected in

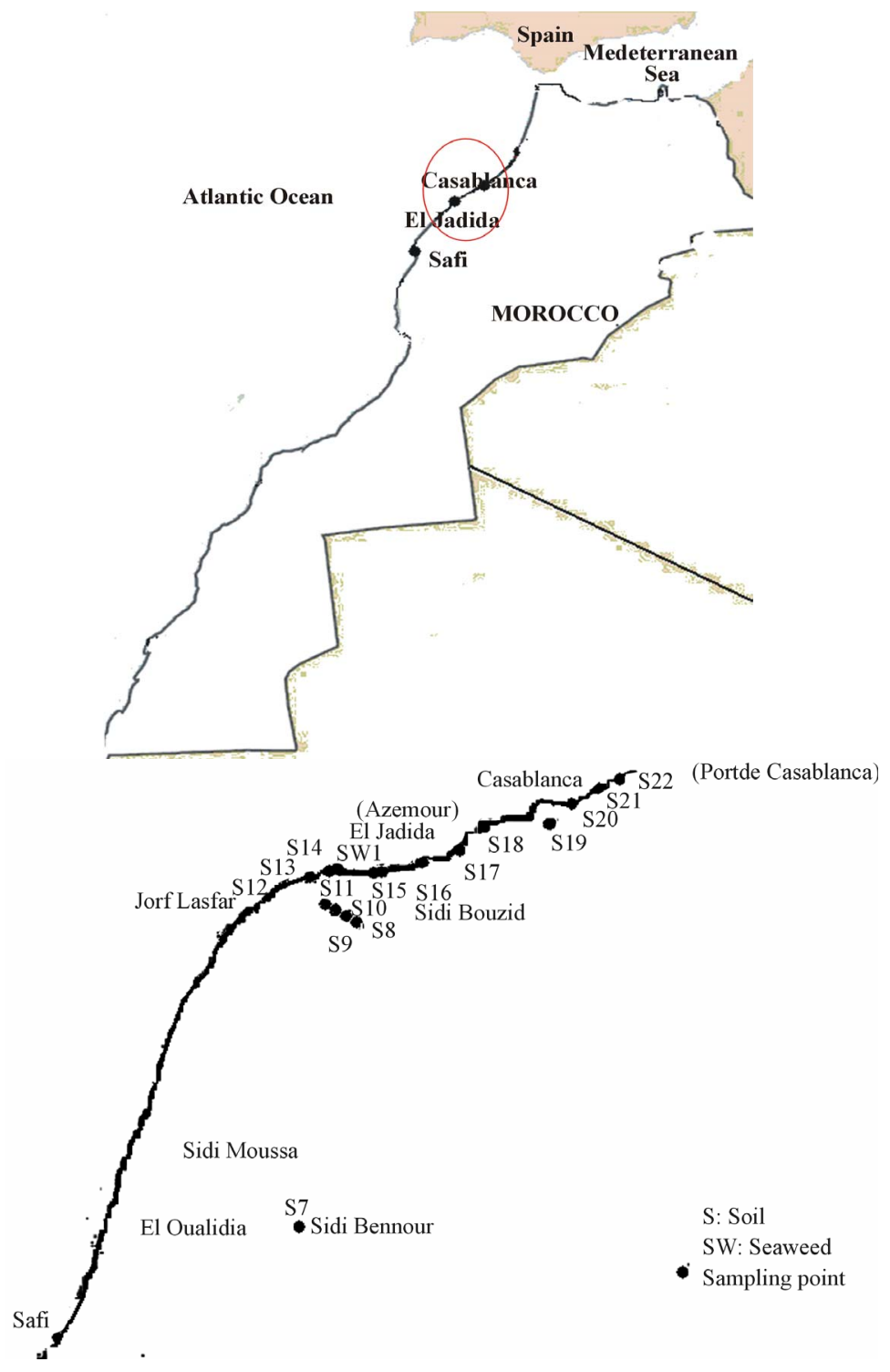

Figure 1. The geographic situation of the studied areas. 
the region of Casablanca: Sidi Abderrahman, Al Hank near the mosque Hassan II and in the port of Casablanca.

The determination of the content of elements, in particular trace element, by the analytical method PIXE requires beforehand a specific study of the sample. These last one are then subjected to the SEM (Electronic Microscopy with Sweeping) and the EPMA methods (Electron Microprobe Analysis) to verify the morphology, the homogeneity of the sample, and to determine the composition of major elements of the sample which we shall analyze. We show below a typical SEM pictures obtained from some taken samples (Figure 2).

Associating the SEM technique with appropriate detectors allows the study of microanalysis X, the elementary analysis [3]. In this work, we used this last technique to obtain the composition of samples in major elements. Other SEM analyses were made in the BRGM (France). A typical spectrum and the contents in major elements of one of the taken samples (S12) obtained by this technique are given in Figure 3. Afterward about $2 \mathrm{~g}$ of every sample was compacted in the form of cylinder of $1.5 \mathrm{~cm}$ in diameter and few $\mathrm{mm}$ in thickness with a mechanic press before being stuck on an aluminum disk for the punctual analysis of trace by the PIXE technique. It was performed with the nuclear miniprobe available on the laboratory CEMHTI-CNRS in Orleans (France).

As in previous study [4], we used for the experience, the accelerator Van De Graaff of the CEMHTI-CNRS. Samples are irradiated with $2.5 \mathrm{MeV}$ protons beam under a vacuum of the order of $10-6$ mbar. The works realized by $[5,6]$ reveal the details of the application of this method. To optimize our results, to make sure of the reproducibility of the method and of the homogeneity of samples, we swept almost all the surface of each sample by realizing different four positions of measures during 30 minutes.

The visualization of the target during irradiation is made by typical endoscope Olympus HMTV-1H100-04 . The beam of ions stemming from the accelerator can be irregular in the time. So the total charge received by the target was controlled before and after the irradiation respectively by the rotating finger and the Faraday cage. The X-rays stemming from the target irradiation were collected by $\mathrm{Si}(\mathrm{Li})$ detector. This detector with dispersive energy is characterized by $3 \mathrm{~mm}$ of Si crystal, $30 \mathrm{~mm}^{2}$ nominal surfaces. Its energy resolution at $5.9 \mathrm{keV}$ is 148 $\mathrm{eV}$. The dead time of the $\mathrm{Si}(\mathrm{Li})$ detector is $25 \mu \mathrm{s}$. The detector is placed at a $135^{\circ}$ angle with respect to the beam axis and is $2.4 \mathrm{~cm}$ distant from the target. To avoid breaking the vacuum during experience, eliminating the action of backscattering protons and attenuating the intensity of the X-rays coming from major elements, we used absorber filter placed in front of the detector. We can use up to three filters [7].

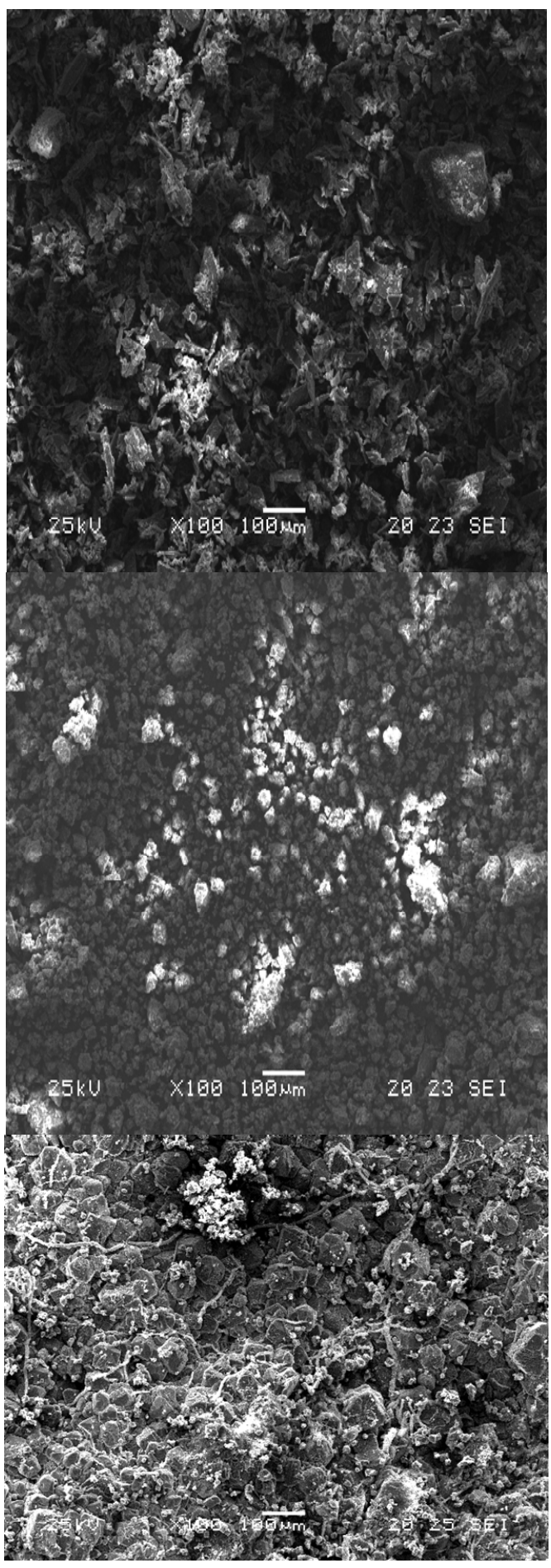

Figure 2. Typical picture of pounded and dried samples obtained by SEM.

For our experiences we used two filters: one in be to avoid pile up effects and the second in Al with a hole in its centre. It's a funny filter which was used to attenuate heavy elements X-rays and to allow those of the light elements to pass into the centre. We used standards to avoid errors and calibrate the method. These standards 
allowed us to obtain the instrumental factor $\mathrm{H}$, necessary for the treatment program of the spectrum to transcribe peaks in concentration.

\section{RESULTS AND DISCUSSION}

The spectrum in energy obtained corresponds to the $\mathrm{K}$ and L X-rays of various elements contained in the sample superposed on a continuous background. With Gupix software, equipped with considerable database, we have calculated theoretical spectrum which is juxtaposed to the experimental spectrum [4].

Once a good concordance is obtained, that is a minimum distance between these two spectrums, peak surfaces are transcribed in concentration through the instrumental factor H. Data obtained for major element and trace element's concentrations of the studied samples were recorded in Tables 1-4.

These results confirm those obtained during the first analysis of the samples where we identified major elements contained in samples (Figure 3).

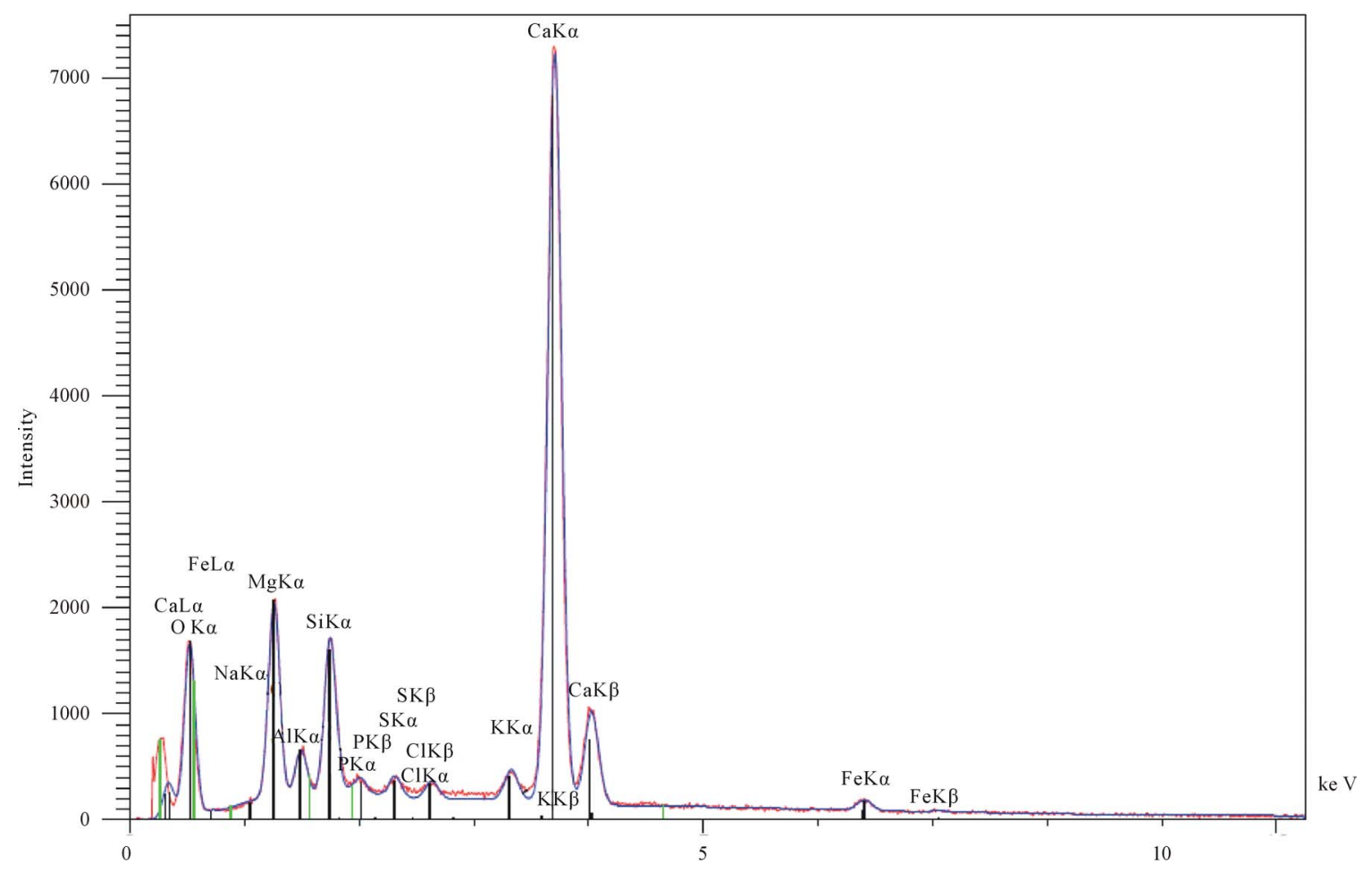

Figure 3. Spectrum of sample number S12 (Analysis made to the BRGM-Orleans France).

Table 1. Concentration (\%) in major element of samples collected inside lands of the Doukkala plain (upstream in the Safi-El Jadida area).

\begin{tabular}{cccccccccc}
\hline Samples & $\mathrm{Si}$ & $\mathrm{P}$ & $\mathrm{S}$ & $\mathrm{Cl}$ & $\mathrm{K}$ & $\mathrm{Ca}$ & $\mathrm{Ti}$ & $\mathrm{Mn}$ & $\mathrm{Fe}$ \\
\hline $\mathrm{S} 8$ & $19 \pm 0.1$ & 0 & 0 & - & $0.46 \pm 0.01$ & $44 \pm 0.02$ & $0.34 \pm 0.008$ & $0.04 \pm 0.003$ & $1.4 \pm 0.01$ \\
$\mathrm{~S} 9$ & $6.6 \pm 0.1$ & 0 & $2.2 \pm 0.03$ & $5.57 \pm 0.02$ & $4.14 \pm 0.01$ & $20.4 \pm 0.03$ & $0.19 \pm 0.007$ & $7.24 \pm 0.01$ & $36.06 \pm 0.03$ \\
$\mathrm{~S} 10$ & $13.5 \pm 0.2$ & 0 & 0 & 0 & $1.1 \pm 0.01$ & $47 \pm 0.04$ & $0.55 \pm 0.01$ & 0 & $1.36 \pm 0.007$ \\
$\mathrm{~S} 11$ & $43 \pm 0.6$ & 0 & $0.09 \pm 0.01$ & - & $3.6 \pm 0.01$ & $2.1 \pm 0.01$ & $1.17 \pm 0.006$ & $0.01 \pm 0.0007$ & $3.43 \pm 0.006$ \\
S12 & $3.6 \pm 0.1$ & 0 & $0.54 \pm 0.01$ & $0.31 \pm 0.006$ & $0.69 \pm 0.01$ & $52 \pm 0.03$ & $0.13 \pm 0.007$ & $0.32 \pm 0.04$ & $0.52 \pm 0.004$ \\
S13 & $26.8 \pm 0.1$ & 0 & $1.17 \pm 0.01$ & $8.71 \pm 0.01$ & $1.98 \pm 0.01$ & $39.3 \pm 0.03$ & $0.8 \pm 0.01$ & $0.06 \pm 0.005$ & $2.02 \pm 0.006$ \\
S14 & $21.4 \pm 0.1$ & $1.43 \pm 0.04$ & $0.8 \pm 0.01$ & $16.14 \pm 0.02$ & $1.22 \pm 0.01$ & $43 \pm 0.1$ & $1.09 \pm 0.01$ & - & $3.63 \pm 0.01$ \\
S15 & $2.34 \pm 0.08$ & 0 & $0.04 \pm 0.01$ & $1.24 \pm 0.008$ & 0 & $78 \pm 0.1$ & 0 & 0 & $0.32 \pm 0.006$ \\
SW1 & $0.61 \pm 0.01$ & 0 & $7.33 \pm 0.01$ & $33 \pm 0.02$ & $9.71 \pm 0.01$ & $5.23 \pm 0.01$ & $0.02 \pm 0.002$ & $0.01 \pm 0.001$ & $0.04 \pm 0.0006$ \\
\hline
\end{tabular}


Table 2. Concentration ( $\mathrm{pm}$ ) in trace elements of samples collected inside lands of the Doukkala plain (upstream in the Safi-El Jadida area).

\begin{tabular}{cccccccccccc}
\hline Samples & $\mathrm{Cr}$ & $\mathrm{Cu}$ & $\mathrm{Zn}$ & $\mathrm{As}$ & $\mathrm{Br}$ & $\mathrm{Sr}$ & $\mathrm{Y}$ & $\mathrm{Zr}$ & $\mathrm{Hg}$ & $\mathrm{Pb}$ \\
\hline $\mathrm{S} 8$ & $845 \pm 198$ & $342 \pm 22$ & $61 \pm 5$ & $38 \pm 3$ & $48 \pm 9$ & 0 & 0 & $70 \pm 6$ & 0 & $64 \pm 7$ \\
$\mathrm{~S} 9$ & $17,041 \pm 267$ & $9672 \pm 56$ & $172,709 \pm 155$ & $4515 \pm 105$ & $337 \pm 23$ & $157 \pm 20$ & 0 & $66 \pm 12$ & $453 \pm 56$ & $21,271 \pm 261$ \\
S10 & 0 & $250 \pm 17$ & $112 \pm 10$ & $27 \pm 5$ & $166 \pm 18$ & $45 \pm 6$ & 0 & $67 \pm 8$ & 0 & 0 \\
S11 & $847 \pm 52$ & $111 \pm 6$ & $59 \pm 4$ & $28 \pm 2$ & $303 \pm 9$ & $75 \pm 3$ & $54 \pm 4$ & $495 \pm 7$ & $13 \pm 2$ & $32 \pm 4$ \\
S12 & 0 & $181 \pm 10$ & $65 \pm 6$ & $36 \pm 3$ & $11 \pm 2$ & $196 \pm 6$ & $13 \pm 2$ & $28 \pm 5$ & 0 & 0 \\
S13 & 0 & $1126 \pm 16$ & $195 \pm 8$ & 0 & $130 \pm 4$ & $479 \pm 8$ & 0 & $100 \pm 15$ & $74 \pm 13$ & $369 \pm 15$ \\
S14 & 0 & $275 \pm 14$ & $533 \pm 10$ & $38 \pm 3$ & $787 \pm 10$ & $443 \pm 10$ & $44 \pm 4$ & $142 \pm 9$ & $66 \pm 11$ & 0 \\
S15 & 0 & $858 \pm 15$ & $114 \pm 11$ & $213 \pm 4$ & $25 \pm 2$ & $2888 \pm 18$ & 0 & 0 & 0 & 0 \\
SW1 & 0 & $1081 \pm 14$ & $72 \pm 5$ & $80 \pm 13$ & $1190 \pm 12$ & $344 \pm 14$ & 0 & 0 & 0 & $1404 \pm 26$ \\
\hline
\end{tabular}

Table 3. Concentration (\%) in major elements of samples collected entrance to the Casablanca area (downstream to the Safi-El Jadida area).

\begin{tabular}{cccccccccc}
\hline Samples & $\mathrm{Si}$ & $\mathrm{P}$ & $\mathrm{S}$ & $\mathrm{Cl}$ & $\mathrm{K}$ & $\mathrm{Ca}$ & $\mathrm{Ti}$ & $\mathrm{Mn}$ & $\mathrm{Fe}$ \\
\hline $\mathrm{S} 7$ & $34 \pm 0.06$ & 0 & $0.1 \pm 0.004$ & $0.02 \pm 0.002$ & $2.1 \pm 0.01$ & $3.73 \pm 0.01$ & $0.38 \pm 0.002$ & $0.026 \pm 0.0009$ & $1.75 \pm 0.01$ \\
$\mathrm{~S} 16$ & $1.56 \pm 0.06$ & 0 & $0.62 \pm 0.01$ & $0.88 \pm 0.008$ & 0 & $76 \pm 0.03$ & 0 & 0 & $0.28 \pm 0.01$ \\
$\mathrm{~S} 17$ & $24.49 \pm 0.1$ & 0 & $0.23 \pm 0.01$ & $0.44 \pm 0.01$ & $0.52 \pm 0.01$ & $55.44 \pm 0.03$ & $1.09 \pm 0.04$ & $0.12 \pm 0.009$ & $0.98 \pm 0.005$ \\
$\mathrm{~S} 18$ & $28.19 \pm 0.1$ & 0 & 0 & $1.15 \pm 0.01$ & $0.33 \pm 0.005$ & $12.75 \pm 0.01$ & $15.48 \pm 0.02$ & $0.45 \pm 0.005$ & $21.99 \pm 0.01$ \\
$\mathrm{~S} 19$ & $39.97 \pm 0.1$ & $2.46 \pm 0.02$ & $0.03 \pm 0.005$ & $0.09 \pm 0.005$ & $0.94 \pm 0.01$ & $29 \pm 0.03$ & $8.54 \pm 0.02$ & $1.56 \pm 0.004$ & $6.11 \pm 0.01$ \\
$\mathrm{~S} 20$ & $16.4 \pm 0.07$ & 0 & $0.36 \pm 0.01$ & $0.26 \pm 0.01$ & $0.57 \pm 0.01$ & $52 \pm 0.03$ & $0.21 \pm 0.008$ & $0.04 \pm 0.005$ & $1.23 \pm 0.005$ \\
$\mathrm{~S} 21$ & $1.74 \pm 0.02$ & 0 & $0.49 \pm 0.01$ & $0.85 \pm 0.01$ & 0 & $43 \pm 0.02$ & 0 & 0 & $0.13 \pm 0.001$ \\
$\mathrm{~S} 22$ & $17.5 \pm 0.06$ & 0 & $0.88 \pm 0.01$ & $6.64 \pm 0.01$ & $1.5 \pm 0.01$ & $34 \pm 0.02$ & $0.34 \pm 0.004$ & $0.03 \pm 0.002$ & $1.48 \pm 0.01$ \\
\hline
\end{tabular}

Table 4. Concentration (ppm) in traces elements of samples collected entrance to the Casablanca area (downstream to the Safi-El Jadida area)

\begin{tabular}{ccccccccccc}
\hline Samples & $\mathrm{Cr}$ & $\mathrm{Cu}$ & $\mathrm{Zn}$ & $\mathrm{As}$ & $\mathrm{Br}$ & $\mathrm{Sr}$ & $\mathrm{Y}$ & $\mathrm{Zr}$ & $\mathrm{Hg}$ & $\mathrm{Pb}$ \\
\hline $\mathrm{S} 7$ & 0 & $288 \pm 9$ & $149 \pm 6$ & $38 \pm 2$ & $644 \pm 17$ & 0 & $27 \pm 5$ & $50 \pm 11$ & 0 & 0 \\
$\mathrm{~S} 16$ & 0 & $316 \pm 12$ & $55 \pm 8$ & $32 \pm 4$ & $26 \pm 3$ & $4960 \pm 25$ & 0 & 0 & 0 & 0 \\
$\mathrm{~S} 17$ & 0 & $379 \pm 11$ & 0 & 0 & $19 \pm 2$ & $1806 \pm 19$ & $35 \pm 4$ & $156 \pm 11$ & 0 & $144 \pm 13$ \\
$\mathrm{~S} 18$ & $10,291 \pm 242$ & $507 \pm 50$ & $332 \pm 21$ & 0 & $42 \pm 9$ & $104 \pm 9$ & $34 \pm 6$ & $285 \pm 16$ & 0 & 0 \\
$\mathrm{~S} 19$ & $4803 \pm 183$ & $300 \pm 19$ & $184 \pm 7$ & 0 & $94 \pm 11$ & $194 \pm 4$ & $81 \pm 3$ & $3750 \pm 20$ & $48 \pm 18$ & $105 \pm 15$ \\
S20 & 0 & $513 \pm 13$ & 0 & $79 \pm 4$ & 0 & $2311 \pm 16$ & 0 & 0 & 0 & 0 \\
S21 & 0 & $2425 \pm 48$ & $145 \pm 8$ & 0 & $38 \pm 3$ & $3260 \pm 20$ & 0 & 0 & 0 & $187 \pm 15$ \\
S22 & 0 & $1173 \pm 14$ & $367 \pm 6$ & 0 & $133 \pm 4$ & $922 \pm 14$ & $27 \pm 4$ & $93 \pm 15$ & $52 \pm 7$ & $316 \pm 11$ \\
\hline
\end{tabular}

All the samples are almost deprived of $\mathrm{P}$ and $\mathrm{S}$. But almost all of them contain $\mathrm{Cl}, \mathrm{K}, \mathrm{Ca}, \mathrm{Ti}, \mathrm{Zr}, \mathrm{As}, \mathrm{Br}, \mathrm{Mn}$, $\mathrm{Sr}, \mathrm{Mn}, \mathrm{Zn}, \mathrm{Cu}$ and $\mathrm{Fe}$ (Figures 4 and 5). We also noticed that the taken samples were composed of carbon- ates (limestone $\left.=\mathrm{CaCO}_{3}\right)$ and contained halogens $(\mathrm{Cl}$, $\mathrm{Br})$.

There is also a lot of $\mathrm{Si}$ in the samples because it is from sand. The concentrations obtained for the major 


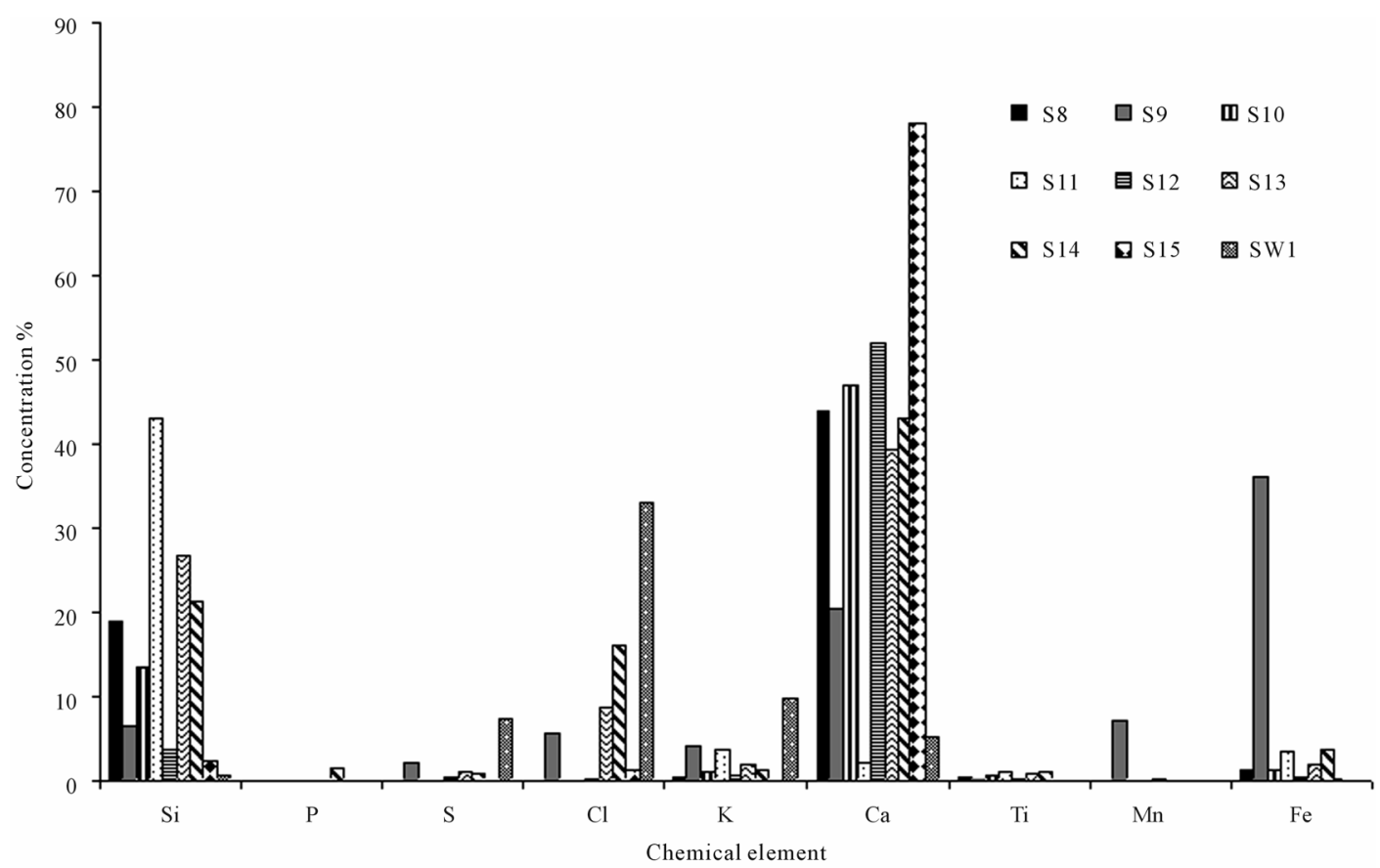

(a)

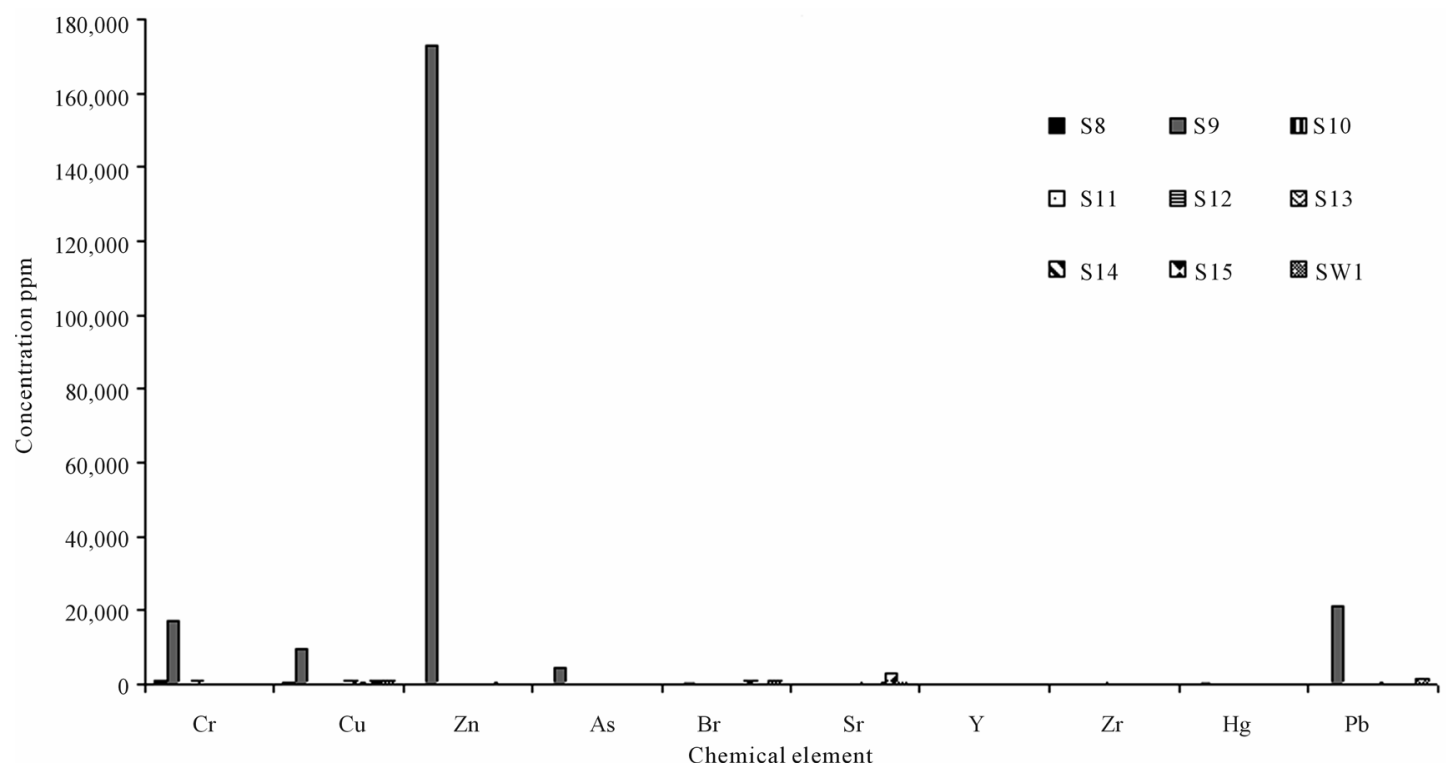

(b)

Figure 4. (a) Concentration of major element in samples taken upstream the Safi-El Jadida area; (b) Concentration of trace element in samples taken upstream the Safi-El Jadida area.

elements ( $\mathrm{Si}, \mathrm{Cl}, \mathrm{K}, \mathrm{Ti}, \mathrm{Ca}, \mathrm{Fe})$ and trace element $(\mathrm{Cr}, \mathrm{Cu}$, $\mathrm{Zn}, \mathrm{As}, \mathrm{Br}, \mathrm{Sr}, \mathrm{Y}, \mathrm{Zr}, \mathrm{Hg}, \mathrm{Pb}$ ) upstream and downstream the Safi-El Jadida industrial complex are respectively given in Tables 1-4.

Samples collected upstream (inside lands between Sidi Bennour and El Jadida) and downstream (in the North of El Jadida by going towards Casablanca) of the mentioned site contained many trace element and element of anthropogenic origin ( $\mathrm{Fe}, \mathrm{Cu}, \mathrm{Zn}, \mathrm{Hg}, \mathrm{Pb}$ ).
They also contained halogen (Figures 4 and 5) but not in important quantity, in particular Br.

This is also true for samples taken from the Safi-El Jadida's Atlantic coast [1]. Besides the wind direction, it could be explained by the fact that:

- Upstream, we note an intense practice of the agriculture because of the natural fertility which the ground offers (absence of phosphor due to the non-use of fertilizers) and the presence of industry in particular of 


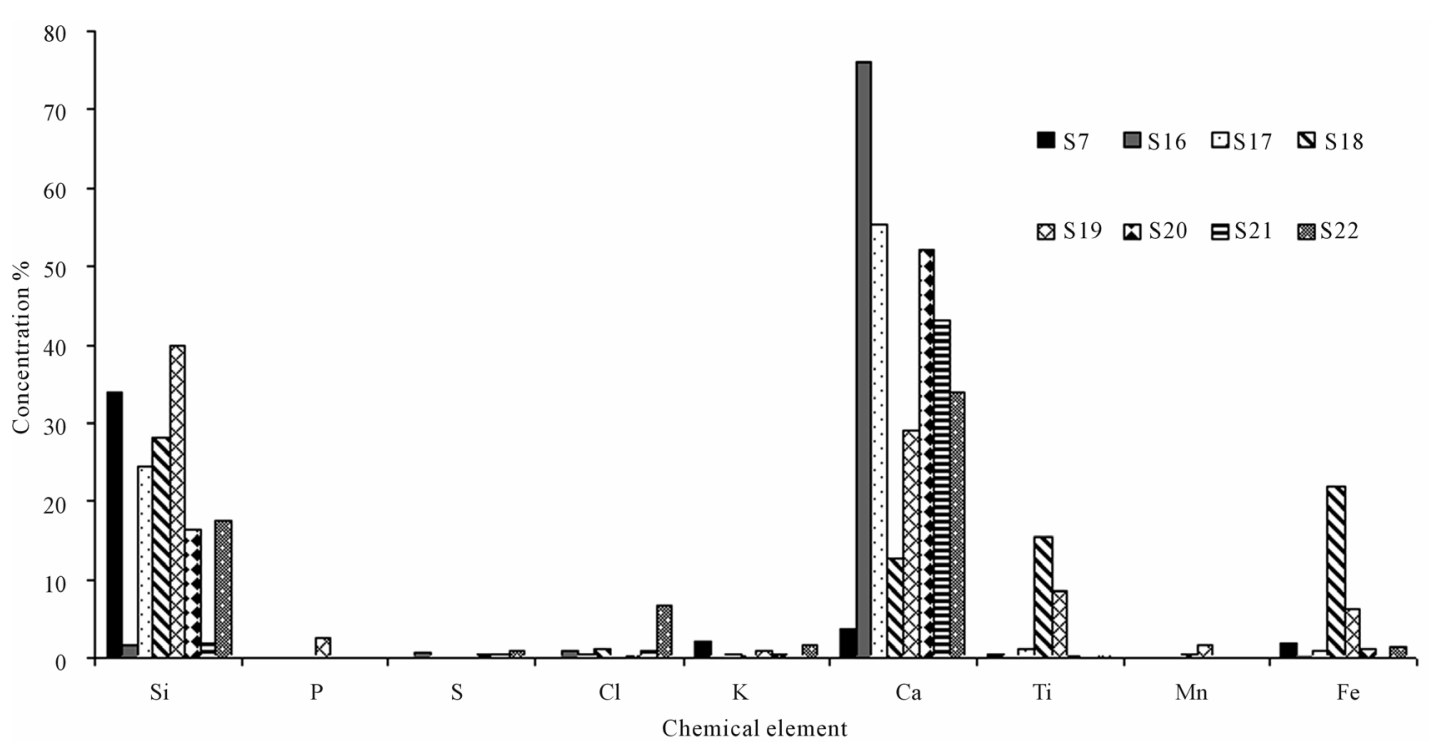

(a)

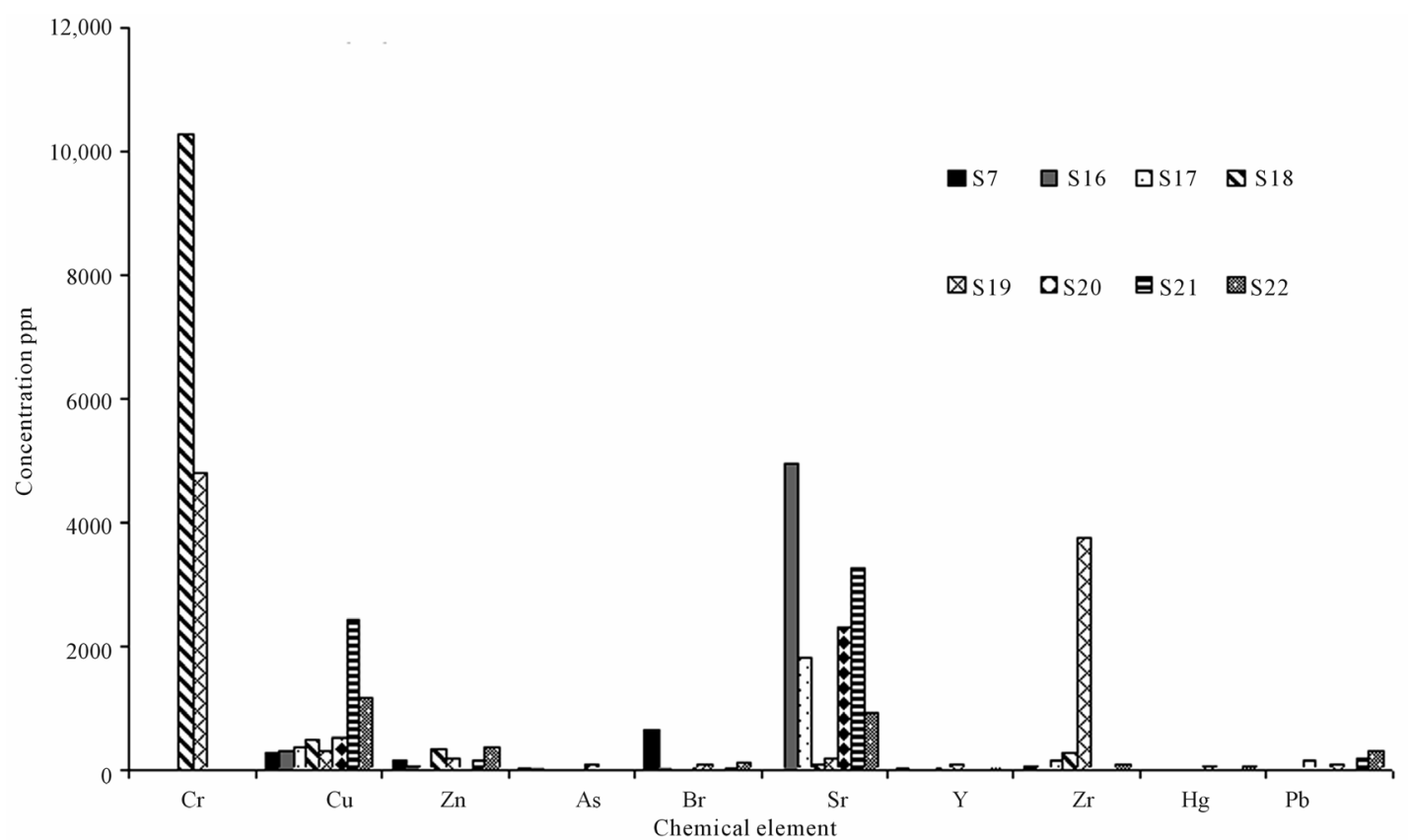

(b)

Figure 5. (a) Concentration of major element in samples taken downstream the Safi-El Jadida area; (b) Concentration of trace element in samples taken downstream the Safi-El Jadida area.

sugar. Besides these samples were taken in a region which is a part of the plain of Doukkala, so we have resemblances in the lithology [8].

- Downstream, the presence of many industries would be the cause.

Upstream samples S8, S10 and S12 - S15 show higher concentrations in calcium much like S16 to S17 and S20 than the others (Figures 4(a) and 5(a)). Upstream samples remind the calcareous faces of the region of the plain from Doukkala and the constitution of the surface (ore of apatite). For samples taken downstream, this concentration of calcium can be due to their localization. Indeed samples are collected in the south border zone of the Doukkala. So it can be the consequence of the erosion phenomenon and/or streaming [9].

We also note that the sample of seaweed (SW1) contains lot of chlorine than the other samples [10]. It is due to the fact that it is seaweed taken in marine environment. In fact seaweed is real sea water filter and excellent bio accumulator (Table 1 and Figure 4(a)).

We notice that the sample S9 taken from a blackish deposit contains higher concentrations in $\mathrm{Cr}, \mathrm{Cu}, \mathrm{Zn}, \mathrm{Ca}$, 
$\mathrm{Hg}$ and $\mathrm{Pb}$ (Figure 4(b)) than the other samples. Its aspect (black powder) and the concentration of metals showed in particular the lead, we think that it is about residues of incineration of garbage and not the consequence of the treatments of phosphate realized in the Jorf Lasfar complex.

Samples coming from or next to fields in particular S7, S11 and S19 contained a lot of silicon than the other samples (Figures 4(a) and 5(a)). These samples are siliceous grounds or sandy grounds, generally poor in fertilizing element. This kind of soil is a part of various type of ground which we find in Doukkala.

Generally we noticed that all samples taken upstream and downstream to the zone situated between Safi and El Jadida don't abound in phosphor (P) and in sulfur (S), while those stemming from this zone abound in relatively high quantity. It means that the presence of these elements is essentially bound to the dominant industrial activities on the Safi-El Jadida

Atlantic coast, in particular the treatment of the phosphate and the use of phosphates fertilizers for farmlands. Indeed the lithology of the coastal between Safi and El Jadida reveals the presence of the gypsum. Weak content of it is considered as an amendment (case of sites upstream).

Samples collected upstream and downstream did not contain nickel trace whereas those of the region Safi El Jadida contained it. We can explain it by the fact that it is an ore which we find in two forms: either in ore combined to the sulphur, probably our case, or in oxidized ore.

We can also add the presence of heavy industries in this zone.

\section{CONCLUSION}

In the present work, we estimated by using the analytical technique PIXE, the impact of the heavy and light elements resulting from industrial activities of Jorf Lasfar complex on soils samples and seaweed neighbouring sites. We noticed that the presence of oligo-elements ( $\mathrm{Si}$, $\mathrm{Cl}, \mathrm{K}, \mathrm{Ti}, \mathrm{Ca}, \mathrm{Fe}$, considered here as major elements) and the elements of anthropogenic origin ( $\mathrm{Fe}, \mathrm{Cu}, \mathrm{Zn}, \mathrm{As}, \mathrm{Pb}$ ) are bound to the quality of grounds (fertile soils in upstream), to the vigour activities in these sites, and also to their lithology. In samples taken upstream and downstream, an absence of phosphor and sulphur was also noticed. These two elements are absolutely bound to the phosphate rock (ore of apatite) and to the treatments realized in the factories of phosphate to obtain the phos- phoric acid and the fertilizers. So we deducted from it that the repercussions of the industrial activities of Jorf Lasfar were localized and do not extend to all of the coast. We noticed also the total absence of nickel which we found in the Safi-El Jadida samples, because we found ore of nickel in two forms: sulphur-binding ore probably the case here and oxidized ore.

\section{REFERENCES}

[1] Gogon, H.D. (2008) Mise en oeuvre de techniques avancées pour la mesure de concentrations naturelles ou polluantes en métaux lourds des sols et de rejets d'eaux de la région de Safi-Casablanca du littoral atlantique. Thesis, University of Cadi Ayyad, Marrakech.

[2] Johansson, T.B., Akselsson, R. and Johansson, S.A.E. (1970) X-ray analysis: Elemental trace analysis at the 10 $12 \mathrm{~g}$ level. Nuclear Instruments and Methods, 84, 141143. doi:10.1016/0029-554X(70)90751-2

[3] Faerber, J. (2004) Microscopie électronique à balayage Microanalyse X par sonde électronique. Institut de Physique et de Chimie des Matériaux de Strasbourg.

[4] Campbell, J.L. and Maxwell, J.A. (1996) Gupix 96: The Guelph PIXE program. University of Guelph, Guelph.

[5] Choï, C.G. (1996) Analyse quantitative par la mini-sonde nucléaire PIXE: Applications aux Sciences de la Terre. Thesis, University of Orléans, Orléans.

[6] Gama, S. (2000) Evènements métallogéniques à W-Bi (Au) à $305 \mathrm{Ma}$ en chataigneraie du canal: Apport d'une analyse multi-spectrométrique (micro PIXE-PIGE et Raman) des matériaux et fluids occlus à l'identification des sources de fluides hydrothermaux. Thesis, University of Orléans, Orléans.

[7] Gama, S.M., Ramboz, C. and Rouer, O. (2001) Accurancy of PIXE analysis using a funny filter. Nuclear Instruments and Methods in Physics Research B, 181, 150156. doi:10.1016/S0168-583X(01)00350-0

[8] Soulet, S. (2000) Etude des effets d'auto-irradiation dans des matériaux à structure apatitique. Thesis, University of Paris-Sud, Sceaux.

[9] Elliot, J.C. (1982) Structure and chemistry of the apatites and other calcium orthophosphates. Elsevier.

[10] Gaudry, A., Zeroual, S., Gaie-Levrel, F., Moskura, M., Boujrhal, F-Z., Cherkaoui El Moursli, R., Guessous, A., Mouradi, A., Givernaud, T. and Delmas, R. (2007) Heavy metals pollution of the atlantic marine environment by the moroccan phosphate industry, as observed through their bioaccumulation in ulva lactuca. Water, Air, \& Soil Pollution, 178, 267-285. doi:10.1007/s11270-006-9196-9 